\title{
An Analysis Scheme for Tropical Wind Fields by the Three-dimensional MASCON Model
}

\author{
By Yurie Heta \\ Disaster Prevention Research Institute, Kyoto University, Uji, Kyoto 611, Japan \\ (Manuscript received 17 October 1991, inrevised form 3 April 1992)
}

\begin{abstract}
For the analysis of the tropical wind fields, Heta $(1990,1991)$ applied the two-dimensional MASCON model, which adjusts and smoothes the interpolated wind data to satisfy the continuity equation at the lower $(850 \mathrm{hPa})$ level. However, the upper level $(200 \mathrm{hPa})$ was evaluated only by interpolation. In the present paper, the analysis scheme of the three-dimensional MASCON model is developed, that provides us with the three-dimensional wind fields $(u, v, \omega)$ over the whole troposphere in the tropical regions using the variational calculus technique as the extension of the previous two-dimensional model. The spatially sparse wind data set of satellite cloud and rawinsonde wind data is adjusted to satisfy continuity equation at all levels consistently. By the use of this new scheme, the tropical wind fields surrounding the same tropical disturbances as the previous papers are reanalyzed and the previous results are certified to be correct.
\end{abstract}

\section{Introduction}

For the analysis of tropical wind fields, satellite cloud wind data is quite effective. We can acquire the twice- or four-times daily upper $(200 \mathrm{hPa})$ and lower $(850 \mathrm{hPa})$ wind data by tracking cirrus and cumulus clouds. In the previous papers (Heta, 1990, 1991), the upper and the lower tropospheric level wind fields in the tropics were analyzed by interpolation at each grid point of $1^{\circ} \times 1^{\circ}$ in latitude and longitude. The lower wind fields were adjusted and smoothed the interpolated field using the two-dimensional Mass Consistent Atmospheric Flux (MASCON) model by Dickerson (1978) to satisfy the continuity equation. However, for simplicity the upper $(200 \mathrm{hPa})$ was not adjusted. It is feared that the upper and lower wind fields lack consistency and some source or sink might appear between the upper and lower levels.

The purpose of the present paper is to describe the new simple three-dimensional assimilation method using the three-dimensional MASCON model, which is an extension of the two-dimensional MASCON method developed by the present author (Heta, 1990, 1991). The wind field calculated by this method satisfied continuity equation at all levels

(C)1992, Meteorological Society of Japan consistently. This paper is a supplement to the previous two papers to certify the previous results as correct and complete the analysis method of the tropical wind fields.

\section{Model description}

The first model of the present author (Heta, 1990) has followed the two-dimensional MASCON model developed by Dickerson (1978) based on Sasaki's variational method (1979). In extending the model into three dimensions, a pressure coordinate $p^{*}$ is adopted in the present system to include the whole troposphere of equatorial area defined by

$p^{*}=\left\{\begin{array}{lr}\left(p-p_{m}\right) *\left(p_{o}-p_{m}\right) /\left(p_{s}-p_{m}\right)+p m \\ p & \left(p \geq p_{m}\right) \\ p & \left(p<p_{m}\right)\end{array}\right.$

where $p_{s}$ is the surface pressure and $p_{o}$ is a constant pressure corresponding to the bottom of the model. As shown in Fig. 1, only the layers below $p_{m}$ are affected by the orography, which is relatively flat in the tropics. $p_{m}$ is given a constant value (in this case, $p_{m}=500 \mathrm{hPa}$ ). This coordinate is a hybrid between the p-coordinate and the $\sigma$-coordinate, and was chosen to incorporate the topography of the tropical Pacific whose highest point is about $700 \mathrm{hPa}$ in New Guinea. 


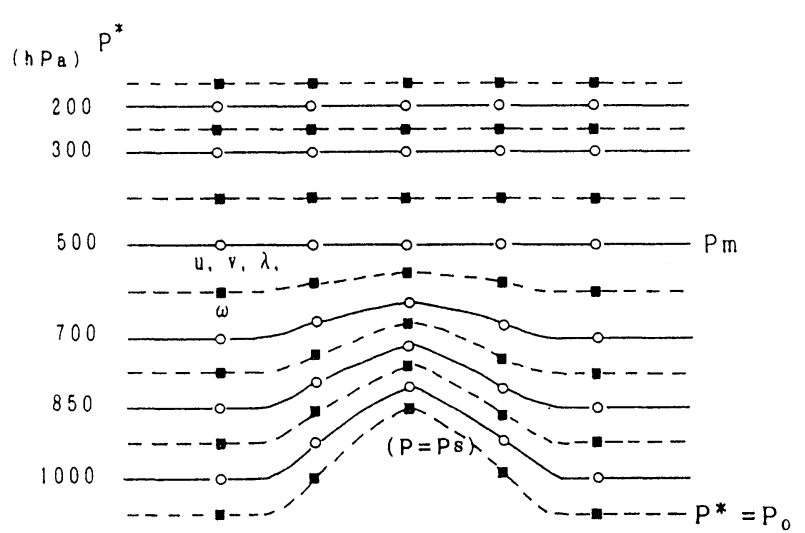

Fig. 1. Vertical grid structure of the model. Solid lines show main levels $(\bigcirc-u, v, \lambda$ and $\mathbf{\square}-\omega)$.

In this coordinate, we define the time change of $p^{*}$ as

$\omega^{*}=d p^{*} / d t=\left(p_{o}-p_{m}\right) \times\left(\omega-v \cdot \nabla_{p^{*}} p\right) /\left(p_{s}-p_{m}\right)$

where $\omega=d p / d t$.

Then the continuity equation of $\left(x, y, p^{*}\right)$ becomes,

$$
\partial(\varepsilon u) / \partial x+\partial(\varepsilon v) / \partial y+\partial\left(\varepsilon \omega^{*}\right) / \partial p^{*}=0
$$

where

$$
\varepsilon= \begin{cases}\left(p_{s}-p_{m}\right) /\left(p_{o}-p_{m}\right) & \left(p \geq p_{m}\right) \\ 1 & \left(p<p_{m}\right)\end{cases}
$$

As $p^{*}$.is basically a pressure coordinate, the whole troposphere can be handled without assumption about air density.

Even though the pressure of the ground surface, $p_{s}$ is strictly a function of time, fixed values are used in this study following climatological relations with heights in the tropical atmosphere given by

$$
p_{s}=1016\left(\exp \left(-0.11746 * Z_{s}\right)-1\right)+p o
$$

where $Z_{s}$ is the height above the mean sea level. The specific functional of three-dimensional variational analysis (Sasaki, 1979) used in the present study is

$$
\begin{aligned}
& E\left(u, v, \omega^{*}, \lambda\right)=\int\left[\left\{\alpha_{1}^{2}(u-\tilde{u})^{2}\right.\right. \\
& \left.\quad+\alpha_{1}^{2}(v-\tilde{v})^{2}+\alpha_{2}^{2}\left(\omega^{*}-\tilde{\omega}^{*}\right)^{2}\right\} \\
& \left.\quad+\lambda\left(\partial u / \partial x+\partial v / \partial y+\partial \omega^{*} / \partial p^{*}\right)\right] d x d y d p^{*}(6)
\end{aligned}
$$

where $x, y$ are horizontal coordinates, $u, v, \omega^{*}$ adjusted velocity components in the $x, y, p^{*}$ directions, respectively, $\tilde{u}, \tilde{v}, \tilde{\omega}^{*}$ the observed variables, $\lambda(x, y$, $p^{*}$ ) the Lagrange multiplier, and $\alpha_{k}$ being Gaussian precision moduli for horizontal $(k=1)$ and vertical $(k=2)$ directions.

The associated Euler-Lagrange equations whose solution minimizes Eq. (6) are,

$$
\begin{aligned}
& u=\tilde{u}+1 /\left(2 \alpha_{1}^{2} \gamma\right) \cdot \partial \lambda / \partial x \\
& v=\tilde{v}+1 /\left(2 \alpha_{1}^{2} \gamma\right) \cdot \partial \lambda / \partial y \\
& \omega^{*}=\tilde{\omega}^{*}+1 /\left(2 \alpha_{2}^{2} \gamma\right) \cdot \partial \lambda / \partial p^{*} \\
& \partial u / \partial x+\partial v / \partial y+\partial \omega^{*} / \partial p^{*}=0
\end{aligned}
$$

The bottom and upper boundary conditions are $\partial \lambda / \partial n=0$, which mean "no-flow-through" boundaries, while the lateral, on the $x$-direction and $y$ direction boundary conditions are open or $\lambda=0$.

In this formulation, from the initial wind field $(\tilde{u}$, $\left.\tilde{v}, \tilde{\omega}^{*}\right)$ at each grid point, we can obtain the adjusted wind ficld $\left(u, v, \omega^{*}\right)$, which satisfies the continuity equation and also fits the observation in a least-squares manner, using the MASCON model. In this process, it is important to interpolate the proper initial wind field $\left(\tilde{u}, \tilde{v}, \tilde{\omega}^{*}\right)$ from the observation. In the next section, the interpolation method is described in detail.

There are some parameters determined in advance for the calculation of the MASCON model. All of them are determined experimently. The ratio of Gaussian precision moduli $\left(\alpha_{1} / \alpha_{2}\right)^{2}$ in Eq. (6) affect the resulting wind field appreciably, though there is no clearly formulated way to settle the value. In the present paper we determine the value of $\left(\alpha_{1} / \alpha_{2}\right)^{2}$, after similar trials to the previous study (Heta, 1991), to be $\alpha_{1} / \alpha_{2}=0.08$, which minimizes the absolute error from the continuity equation with $\overline{|\varepsilon|}$ (Sasaki, 1979).

The absolute values of adjusted $\omega$ are also dependent on the ratio of $\alpha$ 's, because the observational $\tilde{\omega}$ are set to be zero in the present study. If a smaller value of $\alpha_{1} / \alpha_{2}$ is chosen, the absolute value of the resulting $\omega$ gets smaller. However, the horizontal and vertical pattern of $\omega$ is independent of the ratio of $\alpha$ 's.

\section{Interpolation method}

In the MASCON formulation, from the initial wind field $\left(\tilde{u}, \tilde{v}, \tilde{\omega}^{*}\right)$ at each grid point, we can obtain the adjusted wind field $\left(u, v, \omega^{*}\right)$, which satisfies the continuity equation and also fits the observation in a least-squares manner, using the MASCON model. In this process, it is important to interpolate the proper initial wind field $\left(\tilde{u}, \tilde{v}, \tilde{\omega}^{*}\right)$ from the observation. Since a measurement of the vertical velocity $\omega$ is not available, they are initially set to zero, similar to the MATHEW model. Initial values of $u$ and $v$ at the grid point $\left(x, y, p^{*}\right)$ above the $p_{m}$ $(500 \mathrm{hPa})$ level were prepared in a two-dimensional interpolation scheme without respect to an adjustment layer similar to that of Dickerson (1978), as follows:

$$
V i=\sum_{j=1}^{N} S V_{i j} \exp \left(-\beta r j^{2}\right) / \sum_{i=1}^{N} S \exp \left(-\beta r_{j}^{2}\right)
$$


(a)

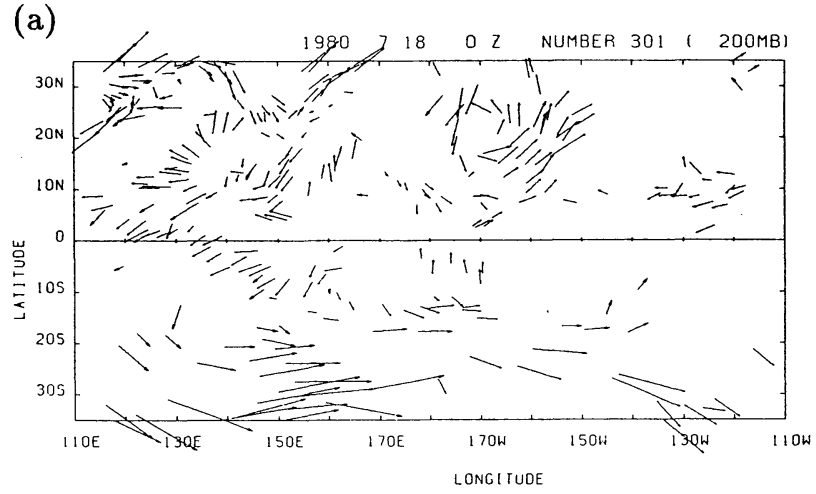

(b)

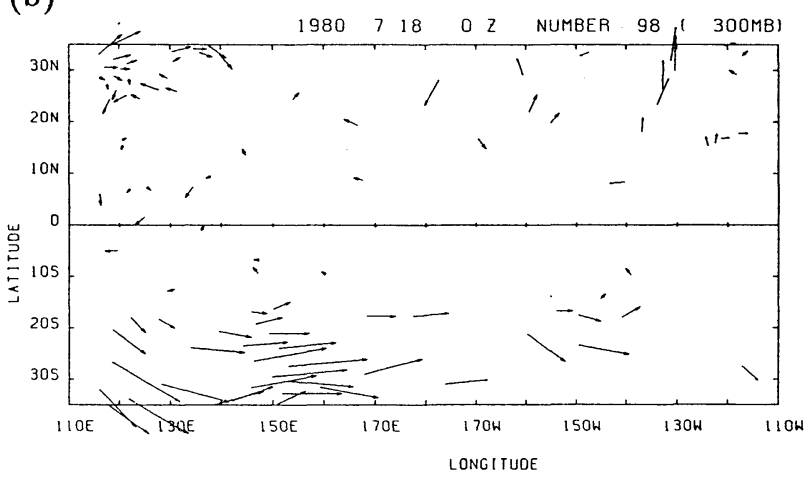

(c)

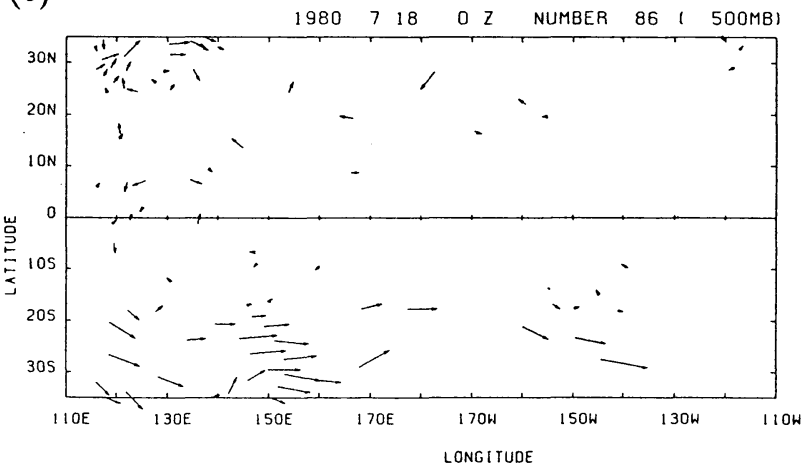

(d)

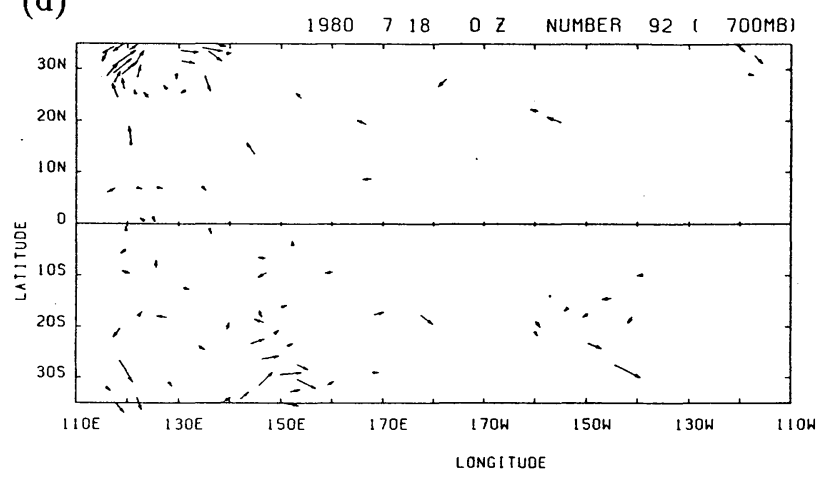

(e)

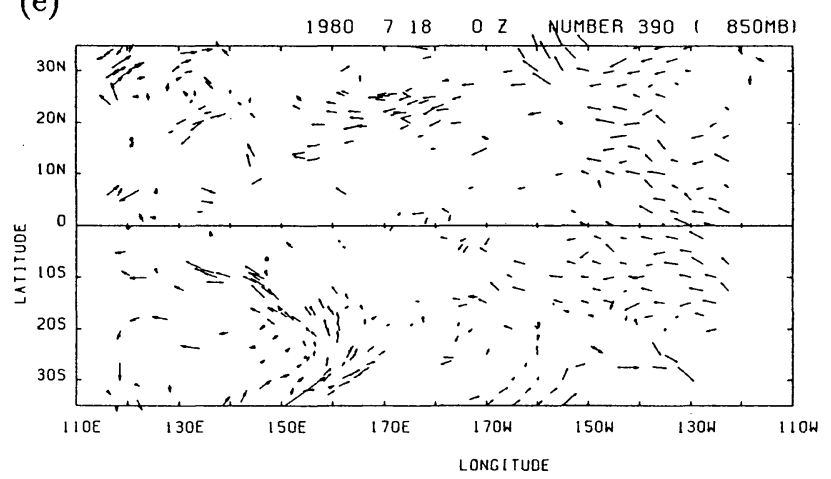

(f)

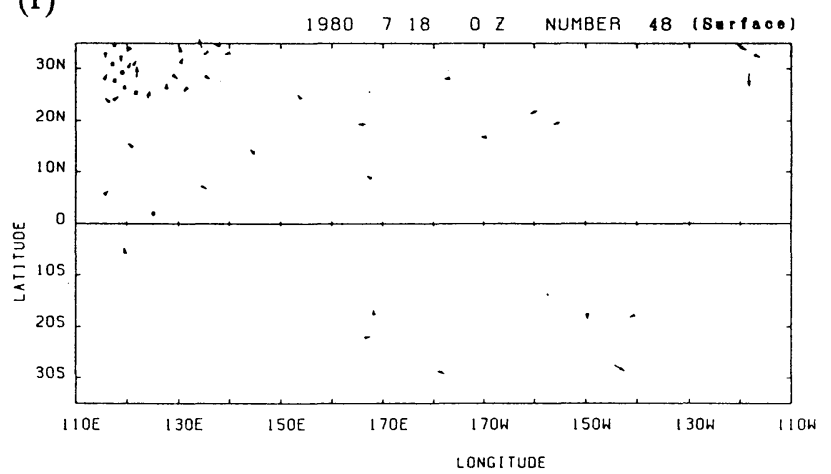

Fig. 2. Distribution of observational wind data at (a) $200 \mathrm{hPa}$, (b) $300 \mathrm{hPa}$, (c) $500 \mathrm{hPa}$, (d) $700 \mathrm{hPa}$, (e) $850 \mathrm{hPa}$ and (f) $1000 \mathrm{hPa}$ levels at 00Z on $18 \mathrm{July,} 1980$.

where $V_{i}$ is the interpolated east-west $(i=1)$ or north-south $(i=2)$ velocity component at the grid point, $V_{i j}$ and $r_{j}$ are the $i$-velocity component and distance to the grid point of the $j$-th closest observation, and $N$ is the number of the closest observations to the grid point that are used for interpolation. $\beta$ is the weight depending on the horizontal distance being $10^{-12}$, the same as the previous two-dimensional MASCON model (Heta, 1990, 1991). For this study we have chosen a value of 5 for $N$ as usual. In addition, we have added the weight, $S$, which varies with the kind of observation. After several trials of changing $S$, we decided on $S=1$ for sonde and $S=$ 0.9 for satellite wind data. In Fig. 2, there is a typical distribution of wind observations. The satellite wind is included only in the $850 \mathrm{hPa}$ and $200 \mathrm{hPa}$ layers following the results of comparison with the rawinsonde data (Hamada, 1982) in the equatorial zone.

Below the layer of $p_{m}$, we adopted the threedimensional interpolation. Then the distance of the grid point of the $j$-th closest observation, $r_{j}$ in Eq. (11) is given by

$r_{j}^{2}=\left(x-\tilde{x}_{0} j\right)^{2}+\left(y-\tilde{y}_{0} j\right)^{2}+\left(p^{*}-\tilde{p}_{0} j\right)^{2} \times W z^{2}(12)$

where $\tilde{x}_{0} j, \tilde{y}_{0} j, \tilde{p}_{0} j$ is the position of $j$-th nearest observational point. The unit of distance is meters. $W z$ is the vertical weight to represent the heterogeneousness of the vertical coordinate. The vertical weight $W z$ has appreciable effect on the resultant wind fields, especially for layers of sparse data, such 
(a)

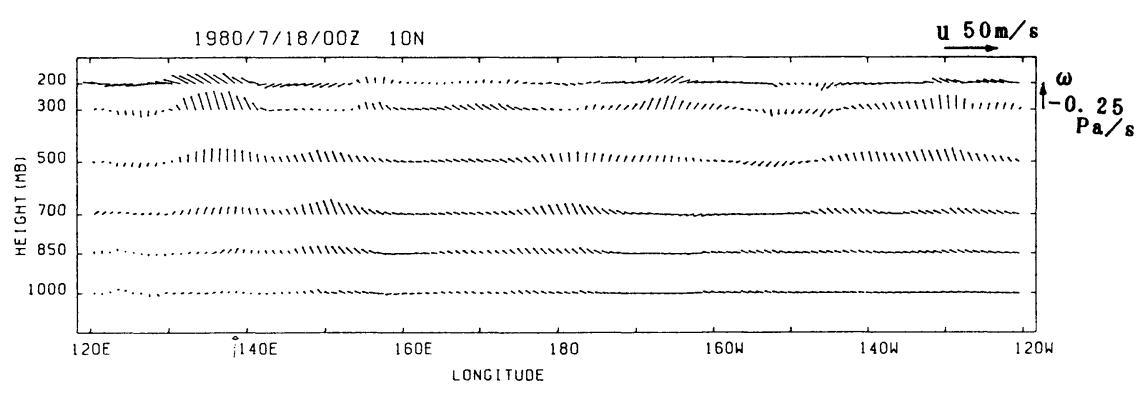

(b)

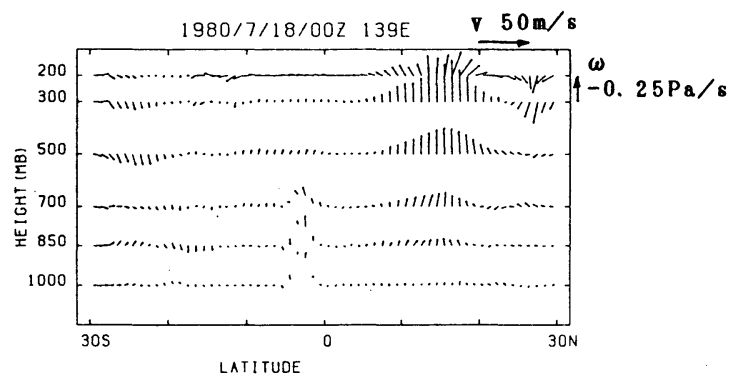

Fig. 3. (a) Vertical-longitudinal structure along the $10 \mathrm{~N}$ zone at $0 \mathrm{Z}$ on 18 July, 1980 adjusted by the threedimensional MASCON model. (b) Vertical-latitudinal structure along 139E. Upward arrows indicate negative values of $\omega$.

as at $1000 \mathrm{hPa}$ or $700 \mathrm{hPa}$. If the value of $W z$ is larger, the interpolation is horizontal, but if it is smaller, the resulting wind fields show a similar pattern for all layers. After several trials, the value of $W z$ was decided to be $50(\mathrm{~m} / \mathrm{Pa})$ for all layers below $p_{m}$, that minimizes the root-mean-square difference between the observational wind and the interpolated wind at the nearest grid point. The values of rootmean-square differences are about $2 \sim 5 \mathrm{~m} / \mathrm{s}$ for the case of $W z=50(\mathrm{~m} / \mathrm{Pa})$.

The interpolation stated above essentially uses simultaneous observations. If the data density changes with time, there is a possibility of gaining better wind field estimates by using the data of a previous time, especially in the data-sparse areas. Since 1987, the satellite wind data has been provided four times a day, though rawinsonde data are still only available once or twice a day. For the analysis of six-hourly wind fields, interpolation with the use of the previous wind data is one of the methods of generating time-consistent wind fields.

The interpolated wind field is appreciably influenced by bad data. A data quality check was done for every case by plotting all data on a map. If there exist bad data, which have improper direction or speed, the data are omitted and not used for the interpolation.

\section{Results}

Using the three-dimensional MASCON model, the tropical wind fields surrounding tropical disturbances on July, 1980 were reanalyzed. Based on the same observational data, wind fields at 6 lev- els $(1000 \mathrm{hPa}, 850 \mathrm{hPa}, 700 \mathrm{hPa}, 500 \mathrm{hPa}, 300 \mathrm{hPa}$, $200 \mathrm{hPa}$ ) are prepared for the area of the equatorial Pacific, 30S $\sim 30 \mathrm{~N}, 120 \mathrm{E} \sim 120 \mathrm{~W}$, where the tropical disturbances appeared, moved and developed into typhoons in the previous analysis. The horizontal wind fields at the $850 \mathrm{hPa}$ and $200 \mathrm{hPa}$ levels are similar to the results from the previous twodimensional analysis (not shown). Figure 3 shows the result of the wind field at $0 \mathrm{Z}$ on 18 July, 1980. A tropical depression is located at $13.4 \mathrm{~N}, 138.9 \mathrm{E}$ at this time, which later developed into Typhoon Joe. Figure 3a shows a longitude-height section at $10 \mathrm{~N}$, and Fig. 3b a latitude-height section at 139E. Strong upward motion is recognized around the tropical depression in both figures. $\omega$ shows its maximum value at the $500 \mathrm{hPa}$ or $300 \mathrm{hPa}$ levels. The absolute value of $\omega$ at the lower level is small compared with the upper levels and the distribution of $\omega$ is quite smooth compared with the upper ones.

Figure 4 shows distribution of at $200 \mathrm{hPa}$ and cloud activity, which is shown by the TBB anomaly from the monthly mean. There is quite good correspondence with each other. Upward-motion area corresponds to a TBB negative anomaly area, that is, an area of higher cloud activity compared with the monthly mean state. The upward-motion area is evident around the areas centered at $138 \mathrm{E}, 15 \mathrm{~N}$ and $160 \mathrm{E}, 5 \mathrm{~N}$ in Fig. 4a. These locations coincide with areas of horizontal divergence at the $200 \mathrm{hPa}$ level in the previous two-dimensional analysis (Heta, 1990, Fig. 7a).

There is a positive $\omega$ region centered on $162 \mathrm{E}, 20 \mathrm{~N}$ at $200 \mathrm{hPa}$ level, which is in correspondence with the 
(a)

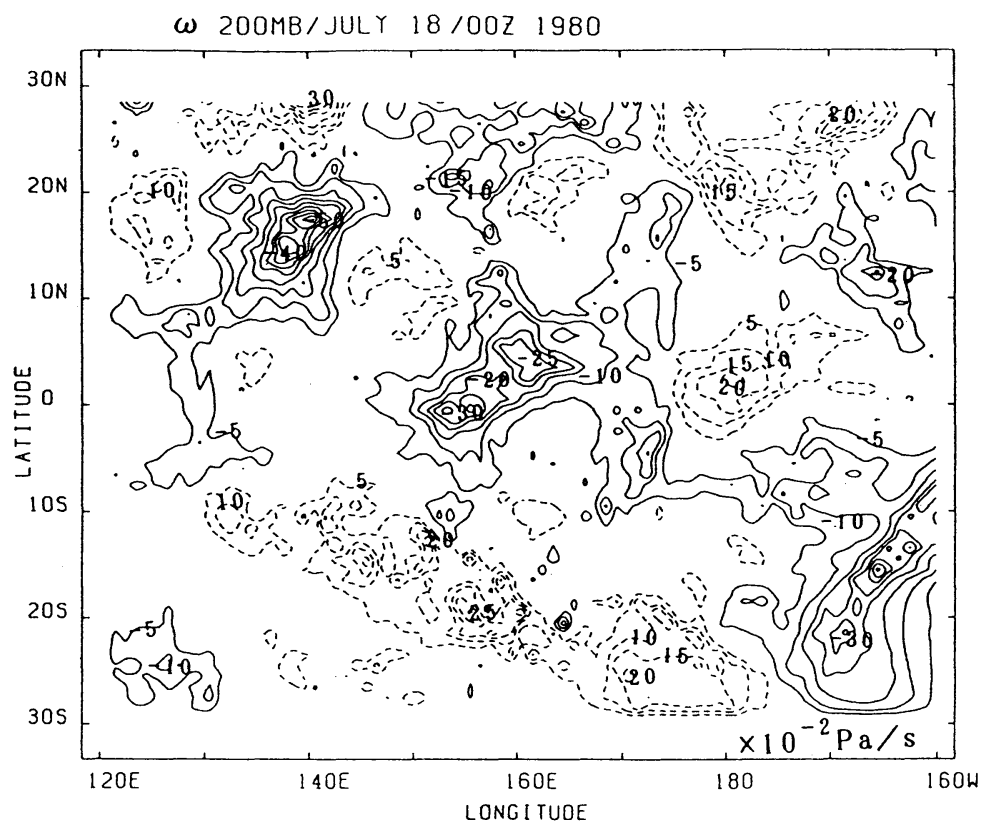

(b)

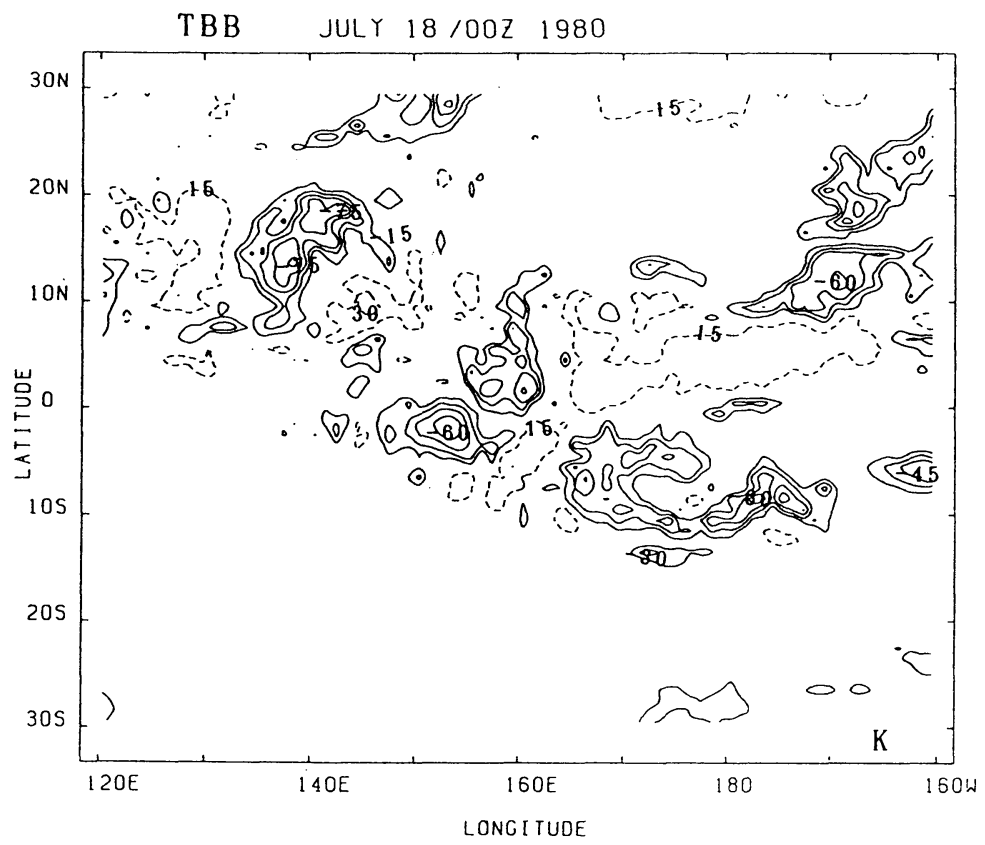

Fig. 4. (a) The distribution of $\omega$ values at the $200 \mathrm{hPa}$ level at $0 \mathrm{Z}$ on 18 , July, 1980. Solid lines show the negative values and broken lines show the positive values. The contour interval is $0.05 \mathrm{~Pa} / \mathrm{s}$. (b) The distribution of anomaly of TBB grid point data from the monthly mean values at 0Z on 18 July, 1980 . Solid lines indicate the negative values and broken lines show the positive values. The contour interval is $15 \mathrm{~K}$.

upper positive vorticity area. Subsidence is evident around the upper positive vorticity area or upper cold low moving westward along the $20 \mathrm{~N}$ zone.

These results show that the pre-typhoon disturbances or the upper cold low analyzed by the previous two-dimensional study are also successfully analyzed by the three-dimensional MASCON model. The previous result was not misleading but, when compared with the present result insufficient. Moreover, we can directly find the distributions of vertical motion in this three-dimensional study.

We can analyze tropical wind fields easily by using the three-dimensional MASCON model. For special observations, we can easily generate finer-mesh wind fields using the new MASCON model for assimilation of the satellite wind and rawinsonde wind data. 


\section{Acknowledgements}

The author expresses her thanks to Prof. Y. Mitsuta of Kyoto University for his continuous encouragement and guidance during this study. Thanks are due to Dr. T. Nakazawa of the Meteorological Research Institute, who kindly provided her with the NOAA OLR data and TBB grid point data utilized in the present study. The author would also like to thank Prof. Y.K. Sasaki of Oklahoma Univ. and Dr. M. Murakami of the Meteorological Research Institute for their helpful comments and suggestions.

\section{References}

Dickerson, M.H., 1978: MASCON-Mass Consistent Atmospheric Flux Model for regions with complex terrain. J. Appl. Meteor., 17, 241-253.
Hamada, T., 1982: Representative heights of GMS satellite winds, Meteorological Satellite Center Technical Note, 6, 35-47.

Heta, Y., 1990: An analysis of tropical wind fields in relation to typhoon formation over the western Pacific. J. Meteor. Soc. Japan, 68, 65-77.

Heta, Y., 1991: The origin of tropical disturbances over the equatorial Pacific. J. Meteor. Soc. Japan, 69, 337-351.

Sasaki, Y.K., 1979: Lecture notes on variational methods for environmental analysis and prediction problems, Severe Storm Research Notes. 1, Disaster Prevention Research Institute, Kyoto University, 174 pp.

Sherman, C.A., 1978: A mass consistent model for wind fields over complex terrain, J. Appl. Meteor., 17, $312-319$.

\section{3 次元 MASCON モデルを用いた熱帯域の風場計算法}

\section{邊田有理江}

(京都大学防災研究所)

著者は以前に熱帯低気圧のまわりの風の場の解析を行ったが、それらは、2 次元 MASCON モデルを用い た対流圈下層 $(850 \mathrm{hPa})$ と内挿風による対流圈上層 $(200 \mathrm{hPa})$ の風の場をもとにしており、上下層は必ずし も consistent ではなかった。そこで、その計算法を拡張し、対流圈全層で連続の式を満たすような風の場を 得るための 3 次元 MASCON モデルを用いた風場計算法を開発した。MASCON モデルでは、ゾンデと衛 星より得られた観測風を連続の式を拘束条件に変分法により補正する。こうして得られた格子点風場は観測 点のある所では最小二乗的に観測值に従い、観測点のない所でも連続の式という物理法則をみたしている。 これによれば、熱帯域の全対流圈の 3 次元風場 $(u, v, \omega)$ が簡単に計算される。この手法を用い、以前に 2 次元で解析した熱帯擾乱を再解析した。以前の解析で得られた擾乱の特徴は、3 次元解析でも確かめられた。 